\title{
EL FEDERALISMO COMO TÉCNICA CONSTITUCIONAL
}

\author{
Federalism As A Constitutional Technique
}

Jorge CHAIRES ZARAGOZA*

Sumario:

I. Introducción II. El federalismo como técnica constitucional III. El federalismo como un proceso IV. Conclusiones

Resumen: El federalismo mexicano está envuelto en una serie de principios que han determinado nuestro sistema competencial entre federación, estados y municipios. Los principios constitucionales que lo definen no son cuestionados porque los consideramos dogmas poco menos que religiosos. Los autores parten de una premisa que de antemano consideran como "válida", en donde los estados deben ser soberanos y el municipio libre porque la Constitución así lo consagra. Sin embargo, esos principios los hemos malentendido y se han utilizado como subterfugios político-jurídicos para la impunidad que, en lugar de servir de límite al poder central, han impedido forjar los debidos pesos y contrapesos en los estados y municipios. El constitucionalismo mexicano consideró el federalismo como una técnica constitucional, que podía adaptarse a cualquier país independientemente de la condición histórica que lo había creado. No obstante, en el presente trabajo intentaremos demostrar que México no tiene las características necesarias para ser un sistema federal.

Palabras clave: Federalismo, Estados, Soberanía, Autonomía, Competencias, Técnica constitucional
Abstract: Mexican federalism is involved in a series of principles that have determined our competences system between federation, states and municipalities. The constitutio- nal principles that define it are not questioned because we consider them dogmas little less than religious. The authors start from a premise that in advance consider as "valid", where the states must be sovereign and the municipality free because the Constitution consecrates it. However, these principles have been misunderstood and have been used as a political-legal subterfuge for impunity, which instead of serving as a limit to the central power, have prevented forging the necessary checks and balances in the states and municipalities. Mexican constitutionalism considered federalism as a constitutional

* Profesor investigador de tiempo completo en el Departamento de Disciplinas Auxiliares sobre el Derecho de la Universidad de Guadalajara. 
technique, which could be adapted to any country regardless of the historical condition that had created it. However, in the present work we will try to show that Mexico does not have the necessary characteristics to be a federal system.

Keywords: Federalism, States, Sovereignty, Autonomy, Competences, Constitutional technique

\section{Introducción}

El federalismo mexicano está envuelto en una serie de principios que han determinado nuestro sistema competencial entre federación, estados y municipios. Dichos principios constitucionales no son cuestionados porque los consideramos dogmas poco menos que religiosos ${ }^{1}$. Sin embargo, los hemos malentendido y se han utilizado como subterfugios político-jurídicos para la impunidad que, en lugar de servir de límite al poder central, han impedido forjar los debidos pesos y contrapesos en los estados y municipios.

Si bien el tema del federalismo ha sido ampliamente estudiado, estos estudios se basan sobre todo en concepciones teóricas que no necesariamente responden a nuestra realidad política y social. Los análisis parten de una premisa que de antemano consideran como "válida", en donde los estados deben ser soberanos y el municipio libre porque la Constitución así lo consagra. La premisa mayor no se cuestiona, por lo que los estudios se reducen a realizar un ejercicio de lógica jurídica simple, carente de sentido crítico práctico: el sistema federal no funciona porque los estados no son libres y soberanos y los municipios no son autónomos.

La gran mayoría de los estudios jurídicos que analizan la problemática del sistema federal mexicano se enfocan en el aumento de las competencias de la federación en perjuicio de los estados y municipios, por lo que apuestan por su fortalecimiento ${ }^{2}$. Los defensores del federalismo han visto cómo el constituyente permanente les ha ido restando

${ }^{1}$ El constitucionalismo mexicano consideró a diversos preceptos de la Constitución como principios básicos, decisiones políticas fundamentales o principios jurídico-políticos fundamentales que, de acuerdo con Jorge Carpizo son las ideas rectoras y las bases del orden jurídico, son los que marcan y circunscriben, son su propio cimiento y esencia, son las columnas jurídico-políticas que lo singularizan y sustentan todas las otras normas constitucionales y legales, las cuales, para algunos autores, eran irreformables. CARPIZO, Jorge (2013), "Los principios jurídico-políticos fundamentales en la Constitución mexicana", Constitucionalismo. Dos siglos de su nacimiento en América Latina, México, UNAM, pp. 809-823. También CANUdAs O., Luis F. (1994), "Irreformabilidad de las decisiones fundamentales de la Constitución", Revista de la Escuela de Jurisprudencia, México, UNAM, núm. 18, 19 y 20, pp. 107 y 108.

${ }^{2}$ Véase, por ejemplo, (2004), Comisión de Estudio para la Reforma del Estado, conclusiones y propuestas, México, UNAM, en donde se establece como el primer acuerdo sobre el federalismo y descentralización el Construir un federalismo auténtico en el que reivindiquen el carácter libre y soberano de los Estados de la Federación como entidades creadoras del Pacto Federal. En el mismo sentido Avances y pendientes para fortalecer el federalismo (2006), México, Centro de Estudios Sociales y de Opinión Pública Cámara de Diputados / LIX Legislatura. Y Valero Flores, Carlos Norberto (2007), Municipio Libre en el marco del federalismo mexicano. Derecho y Obligaciones, México, Cámara de Diputados, quien habla de un federalismo renovado. También a Rabel, Enrique, Nieto, et al. (2013), Federalismo en México, México, Universidad Autónoma de Querétaro - Miguel Ángel Porrúa, p. 112, quienes se refieren a un nuevo federalismo, el cual implica una devolución efectiva de competencias a los estados, lo cual, afirman, no ha sucedido. 
competencias a favor de la federación, por lo que abogan para que no sólo se regrese a la idea originaria del constituyente de 1917 o, incluso de 1824, sino que piden que se avance en dotarlos de plena soberanía. Consideran que uno de los grandes problemas de nuestro país es, precisamente, el excesivo intervencionismo del poder central. Que no se les ha dado a los estados y municipios los mecanismos necesarios para que asuman sus responsabilidades. Los federalistas insisten que se les trate como iguales, que se les deje de ver como "menores de edad" y que se les considere como adultos, por lo que piden su emancipación del poder central.

Se dice que parte del problema tiene que ver con la desconfianza que se tienen las partes integrantes del Estado mexicano. Los órganos nacionales desconfían de los poderes locales y viceversa. Los argumentos más comunes que se escuchan es que los poderes en las regiones no cuentan con las capacidades para implementar políticas públicas y ejercer con eficiencia el gasto, y que la ausencia de pluralidad política genera que no haya los debidos pesos y contrapesos, por lo que la federación tiene que intervenir para controlar los excesos y hacer frente a la incapacidad de la autoridad local. Ante estos argumentos, los defensores del federalismo preguntan ¿si no sería mejor fortalecer las capacidades de los gobiernos de los estados y municipios, en lugar de controlar desde el centro sus actos de gobierno ${ }^{3}$ ?

No obstante, el problema de nuestro sistema de reparto competencial va más allá de la simple idea de fortalecer a los poderes locales mediante un mandato constitucional, tiene que ver con el hecho de que diseñamos un sistema que era ajeno a nuestra realidad política y social. No estábamos preparados para implementar un modelo en el que no se tenía el conocimiento ni la experiencia necesaria para su adecuado funcionamiento. No contábamos con una cultura federal de autogobierno en los estados y, en menor medida en los municipios. Lo peor es que a doscientos años seguimos apostando por un sistema federal que no se ajusta a nuestra realidad. A casi doscientos años de haberse promulgado la primera constitución, seguimos sin contar con una cultura federal de autogobierno en la gran mayoría de los estados y municipios.

El fortalecimiento de los estados y municipios a partir de un federalismo dual de estados libres y soberanos no ha sido la solución, como tampoco el federalismo de coordinación. La descentralización iniciada en la década de los 90`s evidenció la incapacidad de los estados y municipios de hacer frente a sus responsabilidades. Ejemplos de ello tenemos muchos, que nos han obligado a replantear de nueva cuenta el reparto de competencias, incluso las de coordinación y cooperación ${ }^{4}$.

Si bien existen algunos autores que se han atrevido a cuestionar esos principios como Mauricio Merino, Enrique Rabell García, entre otros, quienes reconocen que los argumentos de los defensores del federalismo tradicional están cargados de elementos emocionales, advierten que no será una tarea fácil el dejar atrás las concepciones más rígidas de los enfoques políticos y jurídicos que siguen planteando el federalismo como una suerte de guerra entre las regiones y el centro.

\footnotetext{
3 Raphael, Ricardo (2016), "Federalismo incongruente”, El Universal (25/04/2016). [en línea] disponible en: http://www.eluniversal.com.mx/entradadeopinion/columna/ricardoraphael/nacion/politica/2016/ 04/21/federalismo-incongruente (Consultada 21 de abril de 2016).

${ }^{4}$ Los casos más paradigmáticos los encontramos en la educación y seguridad pública que, de una política de descentralización conforme a un federalismo dual, pasamos a una coordinación y colaboración, para volver a una política de homologación de acuerdo a un federalismo simétrico.
} 
El replanteamiento de estos principios constitucionales que envuelven el federalismo mexicano, nos permitirá afrontar de una mejor manera los retos actuales del sistema de reparto de competencias, sin las barreras conceptuales que se nos han impuesto. Su cuestionamiento nos permitirá hacer diagnósticos pragmáticos de los problemas que enfrentamos como Nación, sin la carga emocional de los dogmas constitucionales que no responden a nuestra realidad actual. Acabar con los debates estériles e interminables sobre la defensa del federalismo dual clásico que sólo ha propiciado el autismo epistemológico. ¿Qué derecho tiene una generación de gobernar a otra? exclamaban los revolucionarios franceses. Para ello, es necesario comenzar por desmitificar los principios constitucionales que dan sustento al federalismo mexicano, para comenzar a construir nuestro propio sistema de Estado de acuerdo a una muy particular realidad social.

En tal sentido, en el presente trabajo abordamos el tema del federalismo mexicano desde otra óptica, comenzando por cuestionar las premisas mayores del sistema federal, que en algunos casos son simples ficciones del constitucionalismo nacionalista mexicano, que se glorificaron para tratar de darle identidad propia a nuestro federalismo.

\section{El federalismo como técnica constitucional}

El constitucionalismo nacionalista mexicano intentó justificar la adopción del régimen federal, pues se consideró que no era un fenómeno histórico sino una técnica constitucional, por lo que el sistema federal norteamericano bien podía ser importado y, como refiere Tena Ramírez ser utilizado por pueblos que no habían recorrido una trayectoria histórica similar a la del país vecino. Que, si el federalismo sirvió para centralizar poderes antes dispersos, como aconteció en los Estados Unidos, también puede ser utilizado para descentralizar poderes anteriormente unificados, como en el caso de nuestro país. Incluso se afirma que la conveniencia y eficacia del sistema federal para cada país no se mide conforme a las necesidades de Norteamérica, sino de acuerdo con las del país que lo hace suyo ${ }^{5}$.

Sin embargo, ello terminó siendo una ficción que aceptamos sin mayores regateos, lo que ha determinado en gran medida no sólo las características de nuestro sistema de reparto de competencias, sino el rumbo de los estudios y análisis de nuestro sistema federal.

México adoptó el modelo federalista como revuelta a la política centralista de la Corona española y como instrumento de unidad ${ }^{6}$. Los constituyentes de 1824 se enfrentaron a un serio dilema en la edificación de una nueva nación independiente, que era el diseñar un sistema estatal que rompiera con un pasado tirano y opresor, a la vez que se tenía que inhibir los intentos independentistas de las distintas provincias y territorios que conformaban la Nueva España.

No discutimos las razones por las que el constituyente de 1823-24 tuvo que decidirse por el régimen federal, no sólo porque era la única alternativa conocida, sino porque efectivamente los hechos históricos así no lo demuestran y, como dice el mismo Carpizo,

\footnotetext{
5 Tena Ramírez, Felipe (2001), Derecho constitucional mexicano, México, Porrúa, p. 108.

6 VÁzquez, Josefina Zoraida (2003), "Constitución Federal de los Estados Unidos Mexicanos, 1824. Contexto histórico del constituyente de 1824", México y sus constituciones, México, FCE, pp. 78-88. Véase también VÁzquez, Josefina Zoraida (1993), "Un viejo tema: el federalismo y el centralismo", Historia Mexicana, ejemplar dedicado a México e Hispanoamérica, Una reflexión historiográfica en el Quinto Centenario. II. 42 (3), pp. 621-631.
} 
de no haberse implementado probablemente México se hubiese balcanizado ${ }^{7}$. Lo que nos cuestionamos es que a la fecha sigamos pensando que es el mejor sistema para nuestro país. Lo que ponemos en tela de juicio son las razones del constitucionalismo nacionalista mexicano para defender hoy en día el sistema federal en México, en un país que histórica y culturalmente no puede ser federal.

Los juristas mexicanos estimaron que plasmar en el texto constitucional los principios generales del sistema federal, sería más que suficiente para el funcionamiento del nuevo Estado mexicano. Que establecer un sistema de reparto de competencias de acuerdo con la doctrina federal dual, en donde las atribuciones del gobierno federal y de los gobiernos estatales están clara y estrictamente definidas y separadas, era el modelo apropiado para romper con nuestra larga y pesada historia centralista y, a la vez, lograr la unidad nacional ${ }^{8}$.

Los teóricos del Estado del siglo XIX creyeron que se podía construir el diseño institucional de cualquier país a partir de dos grandes modelos, según la teoría general del Estado: el sistema constitucional de Inglaterra y norteamericano. O se era un país con un sistema parlamentario o se era un país presidencialista. Si se aspiraba a ser un país parlamentario se debía de seguir las características del derecho constitucional británico. Por el contrario, si se quería adoptar el modelo presidencialista o federalista se debía seguir el modelo norteamericano. En todo caso, podía haber ciertos matices (semipresidencialismo, semiparlamentarismo, federalismo simétrico, de coordinación, etc.), pero siempre a partir de estas dos grandes clasificaciones ${ }^{9}$. En ese sentido, la deducción lógica era que si México no quería ser un régimen centralista entonces debía ser federal, no había más opciones.

La doctrina alemana de principios de siglo XX advirtió sobre la imposibilidad de encasillar a todos los países dentro de la clasificación "general" del Estado. Estas doctrinas generales, de acuerdo con Hermann Heller, cayeron en el error de creer que el Estado puede ser estudiado independientemente de las consideraciones de tiempo y lugar, además de partir de un presupuesto inadmisible, al decir que su estructura formal era algo fijo, invariable e independiente de aquellas condiciones históricas. Heller consideraba que si se quería evitar ese error y si se considera inadmisible ese presupuesto, era entonces necesario abandonar como irrealizable la idea de construir una doctrina general, para limitarse a construir una simple doctrina sin pretensiones de generalidad a la cual se atribuya la terea de investigar la especifica realidad de la vida estatal que nos circunda y de comprender al Estado en su estructura y función actual, en su devenir histórico y en su tendencia evolutiva ${ }^{10}$.

Para el constitucionalista francés Georges Burdeau, el federalismo no es el resultado de la aplicación estricta de un cierto número de normas o recetas, como tampoco implica la adopción de instituciones preestablecidas, sino que procede ante todo de cierta tendencia a incluir la vida fundada en las tradiciones y los intereses locales dentro de un marco que permita satisfacer los imperativos comunes ${ }^{11}$.

\footnotetext{
7 CARPizo, Jorge (1994), Estudios constitucionales, México, Porrúa-UNAM, p. 87.

${ }_{8}$ Por ejemplo, Ricardo Raphael advierte precisamente que con el tiempo hemos extraviado los principios básicos que habrían de normar de manera consistente y sistemática la distribución precisa de responsabilidades. RAPHAEL, Ricardo (2016), op. cit., nota 3.

9 Biscaretti Di Ruffía, Paolo (2006), Derecho constitucional, México, FCE, p. 115 y 188.

${ }^{10}$ Heller, Hermman (1995), Teoría del Estado, México, FCE, pp. 46 y 155.

${ }^{11}$ Burdeau, Georges (1985), Tratado de ciencia política, t. II., México, UNAM, pp. 202 y 203.
} 
En el mismo sentido, Lucas Verdú afirma que una organización construida conforme a simples reglas técnicas de distribución de competencias, que prescinde de elementos ideológicos, carece de sentido. Precisa que no se puede regular el Estado federal tan sólo con los principios de la división de trabajo, como los que organizan un establecimiento de la industria, sino que se trata de coordinar diferentes comunidades políticas cuyos habitantes se preocupan por aspectos políticos determinados que no se pueden soslayar en el ámbito amplio federal ${ }^{12}$.

Autores como Alain-G, Gagnon y Raffaele Lacovino nos hacen ver que no puede darse por sentado que las instituciones democráticas y la protección de libertades son legítimas sólo porque pueden seguir ciertas reglas universales abstractas, como si la democracia liberal pudiera simplemente "enchufarse" a un espacio territorial seleccionado arbitrariamente y el resultado fuera un orden político legítimo ${ }^{13}$.

Pues bien, el diseño federalista en México partió de una teoría general que no tomó en cuenta las singularidades consideraciones de tiempo y lugar. Se consideró que la estructura del Estado federal era algo fijo, invariable e independiente de las condiciones históricas. Que las reglas implementadas en la Constitución de 1824 bien podían ser válidas por siempre, sin necesidad de considerar la tendencia evolutiva de la sociedad mexicana.

\section{El federalismo como un proceso histórico}

\subsection{Cultura federal en los Estados Unidos}

Tocqueville atribuyó el éxito del sistema federal norteamericano, conformado por dos soberanías perfectamente trazadas, a un pueblo habituado desde largo tiempo a dirigir por sí mismo sus negocios y en el cual la ciencia política había descendido hasta las últimas capas de la sociedad. Refiere que México, por el contrario, copió el modelo norteamericano sin tomar en cuenta el espíritu que lo había vivificado. Consideraba el magistrado francés que nuestro país no había podido lograr hacer esa separación entre la soberanía del gobierno federal y la de los estados, por lo que "se estorbaban constantemente entre los engranajes de su doble gobierno". Aclara que los estados y la federación se invadieron mutuamente y no respetaron los límites establecidos por la Constitución, por lo que se veía constantemente arrastrado de la anarquía al despotismo militar y del despotismo a la anarquía $\mathrm{a}^{14}$.

Lucio Levi en su definición de federalismo señala que el conocimiento de un Estado no es completo si no se toman en cuenta las características de la sociedad que permiten mantener y hacer funcionar las instituciones políticas. Por consiguiente, aclara el jurista italiano, si el sistema federal tiene características propias que lo distinguen de los demás, debemos suponer que la conducta de los que viven en ese Estado tiene cierto carácter federal ${ }^{15}$.

De acuerdo con el profesor de la Facultad de Derecho de la Universidad de Toronto Canadá, Jean-François Gaudreault-Desbiens, el federalismo puede prosperar solamente

\footnotetext{
${ }_{12}$ Verdú, Lucas (1976), Curso de derecho político, 2 tomos, Madrid, Tecnos.

${ }^{13}$ Gagnon, Alain-G. y Lacovino Raffaele (2008), Ciudadanía, federalismo y multinacionalismo. Debate sobre la aportación de Quebec, México, Universidad de Guadalajara, p. 48.

${ }^{14}$ Tocqueville, Alexis (1998), La democracia en América, México, FCE, p. 159.

${ }^{15}$ Levi, Lucio, et. al (Coords, 1983), Diccionario de política, Madrid, España, Siglo XXI, p. 627.
} 
si es apoyado por una cultura federal, cuyo crecimiento depende no solamente de actores institucionales, incluyendo los judiciales, sino también de la presencia de una sociedad civil dinámica. Sólo una verdadera cultura federal puede asegurar la preservación del federalismo en el mundo globalizado, donde la presencia de las entidades subestatales parece un impedimento más que una fuente de diversidad ${ }^{16}$.

En consecuencia, por cultura federalista se debe entender como lo dice Tocqueville a una sociedad habituada desde largo tiempo a dirigir por sí misma sus negocios. O como lo señala Lucio Levi en una sociedad que pueda mantener y hacer funcionar las instituciones. O como refiere Jean-François Gaudreault-Desbiens, que el federalismo solamente puede prosperar con la presencia de una sociedad civil dinámica.

En tal sentido, el éxito del sistema federal no puede reducirse a una mera técnica constitucional, basado en un sistema que se limite a enlistar en su texto constitucional las competencias de las partes integrantes del Estado, sino que para que exista ésta debe contar con una base fuerte de autogobierno, lo que hoy en día se conoce como gobernanza en cada entidad federativa, para que el Estado en general funcione. Ya no sólo es hablar de una cultura democrática sino de la eficacia de los gobiernos, de la eficacia de las instituciones de gobierno, es decir, qué tan eficaz es un gobierno para prestar los servicios públicos que la sociedad demanda ${ }^{17}$. En tal sentido, para que sea posible el federalismo en un país es necesario que exista no sólo el respeto del gobierno federal a la vida interna de los estados, así como de estados fuertes que resistan a los inevitables embates del poder central, sino de estados autogobernables, en donde las instituciones locales funcionen y sirvan de contrapeso no sólo a la autoridad central sino también a los abusos del mismo poder local.

Pues bien, esa cultura federal como un elemento definitorio del éxito del federalismo, no ha sido seriamente tomado en cuenta en nuestro país para el diseño de reparto competencial. Para Miguel Caminal el federalismo no es sólo un diseño jurídico-constitucional, sino que es una cultura necesaria para su vida y desarrollo, por lo que considera que la cultura federal es imprescindible. En tal sentido afirma que, para fortalecer la Constitución federal, la división territorial de poderes, la distribución de competencias, las relaciones intergubernamentales y otros elementos que definen los sistemas federales, se necesita fomentar la cultura política federal entre la ciudadanía ${ }^{18}$.

En los Estados Unidos la cultura federal es el fruto de un proceso histórico que se forjó con los siglos, desde mucho antes de que se asentaron en América ${ }^{19}$, como se evidenció con el famoso pacto de Mayflower firmado el 21 de noviembre de 1620 en la cabina de la embarcación por 41 peregrinos adultos que venían a bordo ${ }^{20}$. En el documento se encuen-

\footnotetext{
${ }^{16}$ Gaudreault-Desbiens, Jean-François (2006), "Federalismo y democracia", Boletín de derecho comprado, Instituto de Investigaciones Jurídicas UNAM, Núm. 117, pp. 672-691.

${ }^{17}$ Aguilar Villanueva, Luis F. (2013), Gobernanza y gestión pública, México, FCE, p. 80.

${ }^{18}$ Caminal, Miguel (2002), El federalismo pluralista. Del federalismo nacional al federalismo pluralista, Barcelona, Paidós.

${ }^{19}$ HARTz, Louis (1994), La tradición liberal en los Estados Unidos, México, FCE, pp. 19-46.

${ }^{20}$ Esa cultura federal la podemos rastrear desde mucho tiempo atrás, como lo afirma Emilio Rabasa. La nación que con el transcurso del tiempo se formó, teniendo el sello constitucional propio que le dio el Congreso de Filadelfia, encuentra su ascendencia en toda la tradición inglesa y se remonta hasta Guillermo "El Conquistador". No obstante, el mismo Rabasa nos dice que más bien se ha minimizado: Mucho se ha dicho, ora con desdén que entraña rencor, ora con ligereza que descubre prejuicio, que los Estados Unidos ha sido un pueblo sin tradición cultural de respeto y sin ascendencia espiritual de rango. RABASA,
} 
tran elementos básicos de un pacto social y se establecen ciertos principios semidemocráticos que sirvieron para la edificación de la estructura social de los primeros habitantes asentados en Massachusetts, con una característica distinta a la forma de gobierno implementada por otras colonias.

Las tradiciones y costumbres de los pueblos de Norteamérica no sólo les dieron identidad, sino que determinaron la existencia misma a su sistema federal, el cual tuvo un sentido y razón de ser muy distinto al mexicano, si consideramos la heterogeneidad de sus pobladores provenientes de Europa. A los primeros colonos o inmigrantes ingleses ${ }^{21}$ se les unieron después holandeses, franceses, escoceses, irlandeses, alemanes, galeses, flamencos, suecos, españoles, etc., con culturas, tradiciones, idiomas y costumbres ancestrales europeas muy distintas entre sí, a diferencia de la colonización exclusivamente española en México ${ }^{22}$.

Cada colonia norteamericana forjó su propia identidad de acuerdo a las muy particulares circunstancias en las que se asentaron en el Nuevo Mundo. Nunca hubo un virrey de las trece colonias sino cada una de ellas se gobernaba de manera autónoma, promulgando sus propias leyes e instituciones de forma muy distinta a las demás.

El federalismo fue el basamento de la soberanía interna de las trece colonias independientes, que se prolongó a los estados que conformaron la nueva nación. Sirvió de muro de contención a la imposición de otras formas de pensar, otras religiones, otras lenguas, otras formas de gobierno, otros sistemas de justicia, etc.; sólo así se explica que hoy en día todavía haya estados que practican la pena de muerte o legalicen el uso de la mariguana. No obstante, ese multinacionalismo de las trece colonias sólo fue posible superarlo a través de la expectativa que generaba la creación de una nueva nación, la identidad de una nueva nacionalidad y la exaltación del orgullo norteamericano, por encima de su propia nacionalidad y descendencia. Finalmente, los distintos sentimientos nacionalistas se desdibujaron para conformar una nueva nacionalidad llamada estadounidense. Para cuando estalló la independencia había ya un muy importante grado de homogenización cultural entre los pobladores de las distintas colonias, que permitió que se consumara la alianza federalista sin que cada colonia perdiera su propia identidad. E pluribus unum incluido en el Gran Sello de los Estados Unidos resume la historia de una nueva nación ${ }^{23}$.

Emilio (1986), El pensamiento político del constituyente de 1824, México, UNAM, Instituto de Investigaciones Jurídicas, p. 11 y 12.

${ }^{21}$ Huntington, Samuel P. (2004), ¿Quiénes somos? Los desafíos a la identidad nacional estadounidense, México, Paidós, pp. 62-70.

${ }^{22}$ Lo mismo podemos decir de países federales como Alemania, que su etnogénesis se remonta a las diversas tribus germanas pre-romas. El Estado federal alemán se crea por medio de un proceso de unificación de los distintos pueblos germanos en 1871. En este contexto el federalismo cumplía esencialmente una función de integración, al posibilitar la unidad a partir de la pluralidad. RoviLA, Enoch Alberti (1986), Federalismo y cooperación en la República Federal Alemana, Madrid, Centro de Estudios Constitucionales, p. 12. El federalismo suizo es otro ejemplo clásico de la conformación multinacional. La federación helvética tiene sus raíces dentro de una larga historia que lo explica y permite comprenderlo, que es el esfuerzo emprendido, a partir de finales del siglo XIII, por pequeñas comunidades con culturas y tradiciones muy distintas, con distintos idiomas, religiones y formas de gobierno, deseosas de liberarse de toda sujeción, de afirmar su autonomía y de manejar ellas mismas sus propios asuntos. DominicE, Ch. (1978), "El federalismo en Suiza", Boletín de Derecho Comparado, Instituto de Investigaciones Jurídicas, UNAM, núm. 33, pp. 255-311.

${ }^{23}$ Huntington, Samuel P. (2004), op. cit., nota 21, p. 68. 
En los Estados Unidos a pesar de su rompimiento con Inglaterra, no se trastocó de forma radical la vida interna de las colonias, sino que representó más bien una adaptación de sus instituciones y leyes preconstitucionales o semidemocráticas a las nuevas reglas al Estado constitucional. Incluso algunas colonias promulgaron su propia Constitución antes de la Declaración de Independencia de los Estados Unidos, las cuales sirvieron de inspiración para la Constitución Federal. En ellas se fijaron las bases para un gobierno sujeto a los pesos y contrapesos, además de reconocerse ciertas libertades y derechos ciudadanos, así como mecanismos de defensa de la constitución que sentaron las bases para la judicial review of legislation ${ }^{24}$ del sistema norteamericano.

\subsection{La cultura federal en el México independiente}

No obstante que se quiso justificar el federalismo mexicano como mera técnica constitucional, por lo bien podía adaptarse a un país independientemente de la condición histórica que lo había creado, para algunos autores no dejaba de inquietar el que no existiera un sustento histórico similar al de los Estados Unidos que le diera identidad nacional al federalismo en México, sobre todo, a raíz de las opiniones de algunos autores, particularmente norteamericanos, que se atrevieron a decir que en México el sistema federal jamás había existido, que era federal tan sólo en la teoría y que siempre ha sido centralista ${ }^{25}$.

Así, por ejemplo, Ignacio Burgoa a pesar de que reconoce que el federalismo norteamericano es el resultado de un desarrollo espontáneo y natural de muchos años, el cual, precisa, es definido por la preexistencia de entidades jurídico-políticas soberanas e independientes entre sí, a diferencia de México donde el federalismo no se encauzó por los senderos naturales, señala que no por ello debe considerarse extraña a la evolución política de nuestro país ni efecto de un simple deseo de emulación. Incluso acepta que los estados que constituyeron la federación norteamericana no sólo gozaban, desde que eran colonias, de una especie de autarquía o autonomía gubernativa en las tres funciones estatales, sino que al emanciparse de la metrópoli surgieron a la vida política como entidades independientes de ella y entre sí $^{26}$.

Fue la obra de la historiadora norteamericana Nettie Lee Benson, La diputación provincial y el federalismo mexicano, que les dio a los constitucionalistas nacionalistas mexicanos los argumentos suficientes para demostrar que el federalismo mexicano contaba

\footnotetext{
${ }^{24}$ Virginia proclamó en 1776 la Declaración del Pueblo de Virginia. La Constitución de Vermont de 1777 estableció un amplio catálogo de libertades y derechos ciudadanos. Algunas colonias establecieron mecanismos de defensa de la constitución a través de consejos de censores, conformado por dos representantes por cada ciudad o condado (Pennsylvania y Vermont) o un consejo de revisión integrado por gobernador, el canciller y jueces del tribunal supremo (Nueva York), otros adoptaron el modelo del judicial review of legislation, que sirvieron de precedente para el control difuso de la Constitución estadounidense. Commonwealth vs caton (virginia 1782), Trevett vs Weeden (Rhode Island 1786), Bayard vs Singleton (Carolina del Norte 1787). Blanco VAldÉs, Roberto (1994), El valor de la Constitución: separación de poderes, supremacía de la ley y control de constitucionalidad en los orígenes del Estado Libera, Madrid, Alianza Universidad, pp. 122 y ss.

${ }^{25}$ Tena Ramírez se refiere de manera indirecta al artículo publicado por J. Lloyd Mecham, en 1938 y titulado "The Origins of Federalismo in México". Véase en op. cit., nota 5, p. 112.

${ }^{26}$ Burgoa, Ignacio (1996), Derecho constitucional mexicano, México, Porrúa, pp. 421 y 422.
} 
con una identidad histórica propia y no era una simple imitación servil y extralógica del federalismo de Estados Unidos ${ }^{27}$.

Para los constitucionalistas mexicanos las investigaciones de Nettie Lee Benson derrumbaban la hipótesis de quienes sostenían que el federalismo era ajeno a la cultura institucional y gubernativa del país y que su adopción imponía una descentralización artificial del país. Para ella, la descentralización en nuestro país no ocurrió bruscamente con la adopción del sistema federal, sino que se había ido produciendo de modo gradual a lo largo del tiempo y se desarrolló aceleradamente bajo la Constitución española de 1812 por medio de las diputaciones provinciales. Señala que las diputaciones provinciales creadas por la Constitución de Cádiz dieron forma al federalismo mexicano. Que la génesis de federalismo mexicano puede rastrarse directamente hasta la Constitución establecida en 1812 , la cual hizo provisiones para que cada provincia tuviese un gobierno representativo e independencia política. Incluso afirma que la idea de una distribución territorial de la Nueva España en pequeños reinos o provincias fue el argumento suficiente para pensar en un sistema federal propio ${ }^{28}$.

No obstante, sostenemos que el federalismo era ajeno a la cultura institucional y gubernativa del país y que su adopción impuso una descentralización artificial, como trataremos de demostrar en seguida.

Dos cosas nos interesan analizar de los argumentos de Benson, por un lado, el que se quiera encontrar el génesis del federalismo en una descentralización que se había ido produciendo de modo gradual a lo largo del tiempo y, por otro lado, que el federalismo terminó por consolidarse con las diputaciones provinciales de la Constitución de Cádiz. En cuanto al primer punto hay que decir que se trata más bien de una descentralización administrativa que existe en todos los países federales o no, pero que no justifica el federalismo en nuestro país.

Jesús Reyes Heroles fue uno los primeros autores que difundieron los estudios de $\mathrm{Ne}$ ttie Lee Benson ${ }^{29}$. El peso académico e ideológico de Reyes Heroles influyó de gran manera en los juristas mexicanos para la construcción de un constitucionalismo nacionalista, quienes se negaban a aceptar la idea de que el federalismo mexicano era una imitación servil y extralógica del sistema norteamericano.

Jesús Reyes Heroles, siguiendo las investigaciones de Benson, quiso encontrar los gérmenes del federalismo en algunas acciones y decisiones descentralizadoras que se dieron desde la colonia, a partir de lo dicho por Ramos Arizpe en su memoria presentada a las cortes generales para la promulgación de la Constitución de Cádiz de 1812, quien narró el estado en el que se encontraban las provincias:

\footnotetext{
${ }^{27}$ Autores como Federico Reyes Heroles, Jorge Carpizo, Mario de la Cueva, Reyes Heroles, Emilio Rabasa, Ignacio Burgoa, entre otros, citan la obra de Nettie Lee Benson para justificar el pasado histórico de nuestro federalismo.

${ }^{28}$ Benson, Nettie Lee (2012), La diputación provincial y el federalismo mexicano, México, Colegio de México.

${ }^{29}$ Reyes Heroles, Jesús (2007), El liberalismo mexicano, T. I., México, FCE, pp. 355-359. La historiadora norteamericana Nettie Lee Benson publicó su libro en 1955, un año después Jesús Reyes Heroles publica su famosa obra en donde cita la obra de Benson.
} 
Los Señores Reyes y muchos ministros quienes, aun supuesto este sistema de gobierno, no faltaron buenas intenciones, creyeron templar de varios modos ese poderio excomunal. Mandaron formar en todas las poblaciones, cabildos o municipalidades, y establecer audiencias, universidades, colegios, juntas y sociedades, para que ilustrándose las gentes de las capitales y provincias inmediatas, se proporcionase ciudadanos capaces de defender sus derechos, y representación de aquellos cuerpos, el poderio de los que reunían todo género de mando. Igual efecto ha producido los establecimientos de consulados, y minerías, y aun los de comunidades eclesiásticas, que tanto influyen en la ilustración, y cuanto más tienen en sí de ilustración, y poder, tanto más tiemplan y moderan el reconcentrado en solo un jefe militar ${ }^{30}$.

Reyes Heroles cuestiona ¿si acaso el establecimiento de cabildos, audiencias, universidades, juntas, sociedades, establecimientos de consulados y minerías y comunidades religiosas no fueron factores de descentralización y crearon hábitos de autogobierno en numerosas colectividades? Y precisa que si estas medidas no estaban dirigidas a templar de varios modos ese poderío excomunal los gérmenes de las futuras aspiraciones federales ${ }^{31}$.

El tiempo le debió dar la respuesta a Reyes Heroles, ya que de ninguna manera se moderó ese poderío excomunal de los caciques regionales. Incluso, en el mismo documento, Ramos Arizpe aclara que tales mejoras a favor de aquellos pueblos no han llegado por desgracia después de siglos a las provincias internas ${ }^{32}$. Se debe tomar en cuenta que el establecimiento de esas instituciones se da tanto en regímenes federales como centralistas. El fondo del asunto es cómo se conformaron esas instituciones, si fue a través de un consenso entre los mismos pobladores locales de manera tal que se fue forjando una cultura de autogobierno, como sucedió en las trece colonias, o fueron creadas e impuestas desde la metrópoli, alejando a la población de los asuntos públicos, como fue el caso de México.

En el mismo sentido, algunos historiadores como Josefina Zoraida Vázquez hablan de una federalización clandestina que se venía generando desde el virreinato. Afirma que existen varios elementos que permiten poner en duda que existiera un Estado centralizado, tanto desde Madrid como desde México. Precias que a pesar de los empeños de la monarquía por centralizar y uniformar las instituciones, el control de los reinos de ultramar era obstaculizado tanto por la distancia de la metrópoli como por las dimensiones territoriales de los virreinatos, carentes de comunicación eficientes sumado a la densa orografía, lo que favoreció la formación de intereses locales representados por los municipios en las capitales provinciales ${ }^{33}$.

Sin embargo, esa federalización clandestina a la que se refiere la historiadora no tiene nada que ver con la cultura federal a la que hace referencia Tocqueville, la de pueblo habituado desde largo tiempo a dirigir por sí mismo sus negocios y en la cual la ciencia política había descendido hasta las últimas capas de la sociedad, sino más bien, a la formación de caciques y élites locales, como reconoce Josefina Zoraida Vázquez.

Si bien durante la época colonial hubo una constante lucha entre las autoridades (caciques) de las diferentes provincias y el poder central -quienes constantemente denun-

\footnotetext{
${ }^{30}$ Ramos Arizpe, Miguel (1994), Discursos, Memorias e Informes, México, UNAM, pp. 56 y 57.

${ }^{31}$ Reyes Heroles, Jesús (2007), op. cit., nota 29, p. 362.

${ }^{32}$ Ídem.

${ }^{33}$ VÁzquEZ, Josefina Zoraida (2003), op. cit., nota 6, pp. 78-88.
} 
ciaban las asfixiantes políticas centralistas tanto de la metrópoli cuanto de los virreyes, solicitando que se les concediera a las provincias una mayor autonomía administrativa-, esto no tiene nada que ver con la idea de un pueblo habituado a gobernarse y, por lo tanto, con una cultura federal.

Josefina Zoraida Vázquez dibuja muy bien el panorama histórico del momento. La Corona, nos dice, trató de controlar a los municipios mediante los corregidores pero, por la necesidad de ingresos, los cargos municipales se pusieron a la venta, convirtiéndose en propiedad sobre la que había el derecho de traspasarla como herencia a los descendientes, lo que permitió a las élites locales consolidar su poder. Señala que a esto se superpuso la compleja organización política dividida en reinos, gubernaturas, audiencias $\mathrm{y}$, desde 1786 , en intendencias y provincias internas, lo que terminó por agudizar el fuerte regionalismo que se había generado ${ }^{34}$.

En la misma línea Luis Medina afirma que el federalismo mexicano responde a una evolución original de las cosas, hechos e ideas de largo arraigo en el territorio novohispano. Para confirmar su argumento señala que la historiografía reciente ha puesto en claro que el federalismo no fue el resultado de una imitación disparatada de la constitución estadounidense, pues se adoptó respondiendo a una clara configuración de entidades intermedias entre un poder central colonial que se diluía y los ayuntamientos que se fortalecían. Incluso afirma que es posible rastrear a partir del siglo XVII los regionalismos que contribuyeron decisivamente a dar forma a los futuros estados federados. Señala que hay estudios que asumen a los territorios como sujetos históricos y que ponen énfasis en las formas en que estos se articulan económica y socialmente y van adquiriendo contenido político. Destaca los estudios que han tratado de determinar cómo influyeron el comercio y el desarrollo de la minería primero, y la urbanización y el crecimiento demográfico después para dar lugar a las distintas configuraciones regionales del país. Estos estudios, nos dice Luis Medina, han llevado a determinar cómo la actividad económica entre las regiones y en el interior de ellas crearon y fortalecieron intereses y relaciones, vasos comunicantes de los futuros estados federados. En estos procesos, complejo por las peculiaridades de cada región, se definieron y concretaron distintos intereses que inciden a favor o en contra del federalismo después de la independencia. Intereses mineros, comerciales $y$ agrícolas, juntos o separados, van conformando las identidades regionales ${ }^{35}$.

Lo dicho por Luis Medina Peña sólo termina por confirmar nuestra hipótesis, en el sentido de que la conformación del federalismo mexicano no supuso el respeto a una multinacionalidad o defensa de las costumbres y tradiciones de las distintas regiones, sino la simple defensa de los diferentes intereses económicos de la élite colonial, como termina por reconocer el mismo autor. Que los estudios revelan la formación de élites económicas en las regiones y que la división de poderes vertical en México es producto de tangibles intereses regionales de naturaleza económica y política ${ }^{36}$. Esto es, la razón de que se adoptara el sistema federal en nuestro país no es la defensa de costumbres y tradiciones de las diferentes regiones del país, sino la defensa de dichos intereses de las élites económicas y políticas.

\footnotetext{
34 Ídem.

35 Medina Peña, Luis (2007), Invención del sistema político mexicano. Forma de gobierno y gobernabilidad en el siglo XIX, México, FCE, pp. 122 - 128.

36 Ibidem, pp. 119 y 124.
} 
Se debe tener en cuenta que dicha regionalización es un proceso natural, sobre todo, en un territorio extremadamente extenso como lo era la Nueva España. La división territorial de la Nueva España respondió más bien a intereses económicos y, en su caso, a cuestiones administrativas. Nada tuvo que ver la cultura o los antecedentes étnicos de las poblaciones. Era lógico pensar que la base territorial de los estados de la federación fueran las diputaciones provinciales, y que a su vez su base territorial fueran las intendencias y antes los virreinatos y capitanías de la Nueva España, pero eso no hace a un estado federal. La división territorial de países como Inglaterra, España, Francia o Italia fueron los antiguos reinados, ducados y condados y eso no los hizo países federales.

La cultura política de los habitantes de la Nueva España la podemos resumir en lo dicho por el virrey Marqués de Croix, en el Bando de expulsión de los jesuitas del 25 de junio de 1767: deben saber los súbditos del gran monarca que ocupan el Trono de España, que nacieron para callar y obedecer y no para discurrir, ni opinar a los altos asuntos del Gobierno ${ }^{37}$.

Otra de las conclusiones que nos interesa analizar de la obra de la historiadora norteamericana, es que el federalismo terminó por consolidarse con las diputaciones provinciales de la Constitución de Cádiz. Esta idea se ha aceptado como verdad absoluta y no se cuestiona. Autores como Ignacio Burgoa, Jorge Carpizo, Jacinto Faya o Luis Medina Peña afirman que el federalismo en nuestro país se incubó en las ideas políticas que alimentaron las Cortes de Cádiz en 1811-12 y se reivindicó en el Acta Constitutiva de la Federación mexicana, antecedente inmediato de la Constitución de $1824^{38}$.

Jorge Carpizo sostiene que el germen del sistema federal mexicano se encuentra en las diputaciones provinciales. Afirma que los intentos separatistas de distintas regiones del país son la base del sistema federal, que fue una necesidad y realmente sirvió para unir lo que se estaba desuniendo. El régimen federal no fue una solución de gabinete, teórica, irreal, sino que fue el anhelo de las provincias, por el que lucharon y triunfaron ${ }^{39}$.

En el mismo sentido, Luis Medina Peña señala que la aprobación de la Constitución de Cádiz trajo consigo el reconocimiento formal de los regionalismos preexistentes, que habrán de configurar a las entidades intermedias que en su momento darían forma al pacto federal. Afirma que las disposiciones constitucionales que ordenaban la creación de diputaciones provinciales y el establecimiento de ayuntamientos donde los hubiera fueron los impulsos más importantes que abrieron el camino a la instauración del federalismo en México. Incluso, refiere que una de las principales aportaciones de los constituyentes gaditanos fue trasladar, sin habérselo propuesto explícitamente, el poder político de Madrid a las localidades, las cuales repentinamente se encontraron dotados de personalidad jurídica y política por obra de la propia Constitución ${ }^{40}$.

Pues bien, existe una diferencia muy grande entre la cultura federal Norteamérica, habituada desde largo tiempo a dirigir sus negocios como lo hizo ver Tocqueville, y la

\footnotetext{
${ }^{37}$ Rovira Gaspar, María del Carmen (2009), "Filosofía y humanismo. La obra de los jesuitas criollos mexicanos", Revista de Hispanismo Filosófico, no. 14, pp. 7-23.

${ }^{38}$ BurgoA, Ignacio (1996), op. cit., nota 26, p. 421. CARPIZo, Jorge (1972), "Sistema federal mexicano", Los sistemas federales del Continente Americano, México, FCE, pp. 467 y 469. Incluso, FAYA VIESCA, Jacinto (2014), El federalismo mexicano. Régimen constitucional del sistema federal, México, Porrúa, p. 38.

39 CARPizo, Jorge (1994), Estudios constitucionales, Porrúa-UNAM, p. 85.

${ }^{40}$ Medina Peña, Luis (2007), Invención del sistema político mexicano. Forma de gobierno y gobernabilidad en el siglo XIX. México, FCE, p. 120.
} 
cultura federal mexicana que, como sostiene Nettie Lee Benson, terminó por consolidarse en tan solo una década con la Constitución de Cádiz, lo cual nos viene a confirmar nuestra hipótesis, en el sentido de que el pueblo mexicano no estaba habituado a un sistema federal, es decir, no había una cultura federalista.

Para estos autores, doce años fue tiempo suficiente para impregnar entre la población de las distintas provincias que conformaban la Nueva España, la responsabilidad de autogobernarse y de dirigir por sí misma sus negocios. Doce años para quitarse de encima el pesado yugo de la paternidad española que por más de 300 años habían sufrido, y comenzar a conocer e involucrarse en los asuntos públicos que les concernían, cuando nunca lo habían hecho.

Resulta difícil pensar que en poco más de una década $(1812$ - 1824), se hubiese arraigado entre los ciudadanos de las diferentes provincias una cultura de autogobierno, sobre todo, en una población en donde el analfabetismo rondaba el $99 \%$. Incluso si se quiere encontrar el germen del federalismo desde la época colonial, ya que el pueblo mexicano a diferencia del pueblo de las trece colonias de Norteamérica no participaba de forma alguna en los asuntos de gobierno, no elaboraba sus propias leyes, no elegía a sus gobernantes, no se involucraban en el funcionamiento de las instituciones, ni siquiera la pequeña élite dominante, a quienes se les imponía desde la metrópoli las leyes e instituciones que debían regir en la Nueva España, independientemente que se respetaran o no.

Se debe tomar en cuenta que en México, a diferencia de las trece colonias inglesas, la independencia representó un rompimiento total con la madre patria. La independencia significaba dejar atrás las reglas del antiguo régimen, para pasar a un nuevo modelo basado en las ideas del Estado constitucional totalmente desconocidas en el Nuevo Mundo. Se tenía que comenzar a experimentar con nuevas instituciones y leyes que nunca antes se habían implementado en la Nueva España.

Los problemas que padeció nuestro país en la primera experiencia federalista precisamente por la ausencia de una cultura federal están ampliamente documentados por diversos historiadores, incluida la misma Josefina Zoraida Vázquez quien evidencia los problemas que tuvo el gobierno de Zacatecas y los ayuntamientos para ejercer sus atribuciones. Describe que las juntas censorias que eran órganos de control de los ayuntamientos fracasaron, ya sea porque se excedieron o porque provocaron disturbios. Señala que las quejas por el incumplimiento de las funciones de los ayuntamientos no tardaron en generalizarse, ya sea por carecer de personas aptas o porque las personas que eran idóneas se resistieron a servir en los $\operatorname{cargos}^{41}$. De igual manera, Jaime Hernández Díaz, expone los problemas que tuvo que sortear el estado de Michoacán con el establecimiento de un nuevo sistema político, el cual, afirma, significó un cambio radical en comparación con las maneras de hacer política del virreinato ${ }^{42}$. La situación en el estado de Jalisco no era diferente, Jaime Olveda refiere que las élites regionales continuaron viendo a sus respectivos espacios y

${ }^{41}$ VÁzQuEz, Josefina Z. (2012) "Del federalismo moderado al fracaso radical: Zacatecas", en: Vázquez, Josefina Zoraida y Serrano Ortega, José Antonio (Coords.), Práctica y fracaso del primer federalismo mexicano (1823-1835), México, El Colegio de México, p. 264.

${ }^{42}$ Hernández Díaz, Jaime (2012), "La primera república federal en Michoacán, 1823-1835”, en: Vázquez, Josefina Zoraida y Serrano Ortega, José Antonio (Coords.), Práctica y fracaso del primer federalismo mexicano (1823-1835), México, El Colegio de México, p. 327. 
sus recursos fiscales como un patrimonio exclusivo que no debía compartirse ${ }^{43}$. Carlos Sánchez Silva relata la difícil relación entre el estado de Oaxaca y la federación, sobre todo por la contribución fiscal que el estado tenía que aportar a la federación ${ }^{44}$.

La misma situación acontecía en todos los estados y municipios del país, en donde el nuevo status representaba una expectativa completamente incierta. No había evidencia ni experiencia previa que permitiera suponer el éxito del federalismo en México, porque la sociedad del nuevo Estado mexicano no conocía las nuevas reglas del juego, por lo que no estaba preparada para un cambio de tales dimensiones.

El problema de adoptar una descentralización prácticamente total la hizo ver Fray Servando Teresa de Mier, sin embargo, el constitucionalismo nacionalista mexicano se encargó de desmeritarlo. Teresa de Mier criticaba el hecho de que en las provincias apenas había hombres aptos para enviar al Congreso general, a lo cual con cierto asombro señala: y quieren tenerlos para Congresos provinciales, poderes ejecutivos y judiciales, ayuntamientos etc. etc., No alcanzan las provincias a pagar sus diputados al Congreso central, iy quieren echarse a cuestas todo el tren y el peso enorme de los empleados de una soberanía ${ }^{45}$.

$\mathrm{Al}$ respecto Reyes Heroles si bien reconoce las razones de Mier las minimiza: Es posible que los hombres no tuviesen en aptitud de gobernar el pais; pero, en todo caso, sí lo estaban para gobernar su aldea o su región ${ }^{46}$. Un análisis más objetivo de la realidad mexicana le hubiera dado la respuesta. La realidad es que nunca se tuvo la aptitud de gobernar ni la aldea ni la región. La realidad es que las provincias tuvieron muchos problemas para solventar no sólo los gastos de la administración, sino también la contribución fiscal con la federación, que en no pocas ocasiones no cubrió, ya sea porque no pudo o porque no quiso.

Tena Ramírez reconoce que el sistema federal pasó por una grave crisis de anarquía desde el punto de vista fiscal, sobre todo por la duplicidad desordenada de impuestos y la erección de trabas arancelarias por parte de los gobiernos locales que condujo a la banca rota de la economía naciona ${ }^{47}$. Precisa que en el aspecto político el federalismo propiciaba la formación de cacicazgos locales que, por irresponsables y arbitrarios, hacían nacer en quienes los soportaban el deseo de una mayor intervención de los poderes centrales. Tena Ramírez señala que a pesar de esos sentimientos anticaciquiles, se ha mantenido alerta y combativa la ideología política del federalismo mexicano, vigilando celosamente la supervivencia de las palabras ${ }^{48}$. Ante estos argumentos, cabría preguntarse ¿Por qué? ¿A quién le interesa que se mantengan las cosas igual? ¿Quién quiere seguir manteniendo ese statu quo? ¿Quién se beneficia con ese sistema?

\footnotetext{
43 OlvedA, Jaime (2012), "Jalisco y su primera experiencia federalista", en: Vázquez, Josefina Zoraida y Serrano Ortega, José Antonio (Coords.), Práctica y fracaso del primer federalismo mexicano (18231835), México, El Colegio de México, p. 204.

${ }^{4}$ SÁnchez Silva, Carlos (2012), "De la unidad federalista a la disidencia centralista", en: Vázquez, Josefina Zoraida y Serrano Ortega, José Antonio (Coords.), Práctica y fracaso del primer federalismo mexicano (1823-1835), México, El Colegio de México, pp. 294 y 295.

${ }^{45}$ Mier, Fray Servando Teresa de (2013), "Profecía del doctor Mier sobre la federación mexicana. Sesión del Congreso constituyente del 13 de diciembre de 1823", La revolución y la fe. Fray Servando Teresa de Mier, una antología genera, México, FCE-FLM-UNAM, p. 438.

46 Reyes Heroles, Jesús (2007), op. cit., nota 29, p. 406.

47 Tena Ramírez, Felipe (2001), op. cit., nota, 5, p. 111.

48 Ídem.
} 


\subsection{La cultura federal a 200 años de la independencia}

La falta de una cultura federal al momento de nuestra independencia no tendría mayor relevancia para el constitucionalismo mexicano, si no tuviera consecuencias en la forma en que actualmente ejercen su libertad y su soberanía los estados de la República, y los municipios, su autonomía.

La falta de una cultura federal de autogobierno en la actualidad es más que evidente. Para corroborarlo sólo hay que recorrer el país y darnos cuenta del gran atraso en el que se encuentra la gran mayoría de los estados y municipios de país. De la incapacidad de los gobiernos locales para hacer frente a los servicios públicos más básicos como la seguridad, salud, alumbrado, pavimentación, etc. De los escandalosos actos de corrupción de los gobernadores y presidentes municipales. De la incapacidad de los cuerpos de policía locales para hacer frente ya no sólo a la delincuencia organizada sino a la inseguridad en general. Del nivel de impunidad que impera en las instancias locales de procuración y administración de justicia.

Ahora bien, el hecho de que se afirme que México, al momento de su independencia, no tenía las características para adoptar un sistema federal no nos conduce, inexorablemente, a la afirmación de que necesitamos transitar a un modelo centralista.

Un sinnúmero de libros y artículos se han escrito dando cuenta de la problemática de nuestro sistema de reparto de competencias, con el que bien podríamos llenar una biblioteca completa. La gran mayoría de ellos atribuyen al centralismo los graves problemas de nuestro país, cuando la realidad es que los estados y municipios también han tenido mucha responsabilidad.

Hemos malentendido los artículos 40 y 115 constitucionales para interpretarlos de una manera literal, en el sentido de que los estados son libres y soberanos y los municipios autónomos. Esta interpretación nos ha impedido que se establezcan los debidos controles constitucionales que contrarresten los abusos e incapacidades de los gobiernos locales. En los debates del congreso es muy común que se empantanen las reformas constitucionales por las diferentes interpretaciones al texto constitucional. Por un lado, los defensores a ultranza de un federalismo dual que interpretan dichos preceptos de manera exegética; $y$, por otro lado, los que apuestan por un federalismo más bien flexible o mixto, que entienden que no pueden ser vistos de forma absoluta.

El dilema de todos los modelos federales ha sido siempre el grado de injerencia del gobierno central sobre las llamadas cuestiones internas (domestic affairs) de los estados miembros. Lograr el punto medio de las relaciones federación/estados ha sido el nudo gordiano de los sistemas federales.

No existe un federalismo puro como se ha querido hacer ver. Ningún país sigue un modelo único, ya sea dual, simétrico, asimétrico, cooperativo, de coordinación y colaboración, etc., sino que adoptan diversos modelos de acuerdo con sus propias características y necesidades.

El sistema de reparto de competencias ha dependido de cada país en concreto y tiene que ver con su cultura política. Existen tantas variantes configurativas del federalismo como países federales, que es difícil establecer pautas generales que lo identifiquen de manera unívoca ${ }^{49}$. En algunos países la interferencia del poder federal es mínima, debido

${ }^{49}$ Carbonell, Miguel (2003), "Federalismo en México: principios generales de distribución de compe- 
al nivel de desarrollo político y cultural de sus regiones, lo que que las vuelve autogobernables. En otros responde a la necesidad de lograr la unidad necesaria para su existencia. En otros está directamente relacionado con la diversidad propia de la multinacionalidad y multiculturalidad de las regiones. Mientras que en otros, se debe a la incapacidad de las regiones para autogobernarse, como el caso de México.

De acuerdo con Peter Häberle, no existe una única teoría federal adecuada para todos los supuestos ${ }^{50}$. Precisa que a lo largo del tiempo emergen parcialmente elementos referidos a la concurrencia y la separación, pero también a la cooperación y solidaridad. El jurista alemán está a favor de una teoría federal mestiza que llama también como metamorfosis del federalismo, en la que las características de los distintos modelos y teorías cambian y se mezclan de manera dinámica.

El federalismo dual que se quiso implementar en las constituciones de 1824, 1857 y 1917 demostró su inviabilidad, precisamente por la falta de una cultura federal de autogobierno en los estados y municipios, por lo que se transitó a un federalismo de coordinación y colaboración, aunque tampoco con mucho éxito. Ello nos ha llevado a buscar nuevas fórmulas que permitan una verdadera gobernanza en el país. Ahora estamos experimentando en un modelo que tiende más bien a la unificación y homologación entre los distintos órdenes de gobierno. Se habla ahora de un federalismo simétrico o nacional que permita superar las incapacidades de los gobiernos locales para afrontar sus responsabilidades, sin que necesariamente exista una intromisión centralista dictatorial del gobierno federal ${ }^{51}$.

La evolución o metamorfosis de nuestro federalismo no significa el abandono de los anteriores modelos, sino que en un mismo tema encontramos elementos de cada uno de ellos, por lo que podemos hablar de un federalismo mixto o mestizo como lo refiere Peter Häberle.

En los últimos años hemos sido testigos del aumento de atribuciones del congreso de la unión para dictar leyes generales en distintas materias, como protección civil, turismo, cultura, educación, asentamientos humanos, contabilidad gubernamental, cultura física y deporte, deuda pública, desarrollo forestal, entre otras materias que van más allá de la simple coordinación y colaboración. Incluso en materias que, de acuerdo con el concepto de tradición del reparto de competencias, le corresponderían a la vida interna de cada entidad federativa, como la Ley General de Acceso de las Mujeres a una Vida Libre de Violencia, Ley General de Bibliotecas, Ley General para la Igualdad entre Mujeres y Hombres, Ley General para la Inclusión de las Personas con Discapacidad, Ley General para la Prevención Social de la Violencia y la Delincuencia, entre otras.

Además de que se han creado una gran cantidad de organismos y sistemas nacionales que buscan, más que coordinarse con las entidades federativas y municipios, homologar criterios, políticas y estrategias a nivel nacional, como el Sistema Nacional de Información Estadística y Geográfica, el Consejo Nacional de Evaluación de la Política de Desarrollo Social, la Comisión Nacional de Hidrocarburos y Comisión Reguladora de Energía,

tencias", Anuario de derecho constitucional latinoamericano, Uruguay, Konrad-Adenauer-Stiftung, pp. 379-396.

${ }^{50}$ HäBerle, Peter (2007), “Comparación constitucional y cultura de los modelos federales”, Revista de derecho constitucional europeo, No. 8, julio-diciembre, p. 177

${ }^{51}$ Chaires Zaragoza, Jorge (2018), Federalismo mixto. De un federalismo dual a un federalismo nacional, México, Universidad de Guadalajara. 
el Sistema Nacional de Seguridad Pública, el Instituto Nacional para la Evaluación de la Educación, el Instituto Nacional Electoral, el Instituto Nacional de Transparencia o el Sistema Nacional Anticorrupción.

\section{Conclusiones}

A mediados del siglo pasado algunos juristas, sobre todo extranjeros, comenzaron a cuestionar que México fuera un país federalista, se decía que nuestro sistema federal jamás había existido, que era federal tan sólo en la teoría y que siempre ha sido centralista.

El constitucionalismo nacionalista mexicano reaccionó ante tales señalamientos y ante la imposibilidad de demostrar históricamente la creación del federalismo en nuestro país, de la misma manera como había surgido en los Estados Unidos; se comenzó a justificar su adopción afirmando que era una mera técnica constitucional, por lo que bien se podía adaptar a un país, independientemente de la condición histórica que lo había creado.

Fue la historiadora norteamericana Nettie Lee Benson quien les dio los argumentos necesarios a los constitucionalistas mexicanos para tratar de desmentir las críticas a nuestro sistema federal, al asegurar que se justificaba históricamente a partir de las diputaciones provinciales previstas en la Constitución de Cádiz. Con dichas afirmaciones emergió con mayor fuerza el constitucionalismo nacionalista, que siguiendo las investigaciones de Nettie Lee Benson, defendió la idea de que nuestro federalismo no era una ficción político-jurídico, fruto de la imitación servil y extralógica del sistema norteamericano, sino que tiene su propia identidad histórica.

Incluso, algunos autores como Luis F. Canudas, Jorge Carpizo o Ignacio Burgoa consideraron al sistema federal como uno de los principios jurídico-políticos fundamentales de la Constitución y que, como tal, era irreformable. Ello nos llevó a una especie de autismo académico respecto al análisis del federalismo, donde no se cuestiona, sino que se da por hecho que debemos ser un país federal.

No obstante, como vimos en el presente trabajo, el sistema federal no se reduce a una mera técnica constitucional, sino que debe contar con una fuerte base de cultura federal de autogobierno, como bien lo hizo ver Tocqueville, y que sólo se adquiere con una larga evolución histórica que permita arraigarla entre la población ${ }^{52}$. No hablamos únicamente de una cultura federal en donde el gobierno federal debe respetar la autodeterminación de los estados, sino también de una cultura federal en donde el pueblo esté habituado desde largo tiempo a dirigir por sí mismo sus negocios y en la cual la ciencia política haya descendido hasta las últimas capas de la sociedad.

La cultura federal de los habitantes de los Estados Unidos, la podemos rastrear desde mucho antes de haber desembarcado en Norteamérica. Al contrario de los habitantes de la Nueva España, quienes nunca participaron en los asuntos de gobierno. Incluso la teoría de la historiadora norteamericana viene a confirmar nuestra afirmación, en el sentido de que nuestra cultura federal comenzó a constituirse en menos de diez años, precisamente con las elecciones que se celebraron para el nombramiento a las diputaciones provinciales, en donde por primera vez se toma en cuenta a la población para, por lo menos, elegir a sus gobernantes.

${ }_{52}$ Tocqueville, Alexis (1998), op. cit., nota 14, p. 159. 
Ahora bien, ello no tendría mayor relevancia para el constitucionalismo mexicano si no tuviera consecuencias en el actual sistema de reparto de competencias entre federación, estados y municipios. A prácticamente doscientos años de la promulgación de la Constitución de 1824, la falta de una cultura federal de autogobierno en la gran mayoría de los estados y municipios es más que evidente. Para corroborarlo sólo hay que recorrer el país y darnos cuenta del gran atraso en la que se encuentran muchos de los estados y municipios de país.

En tal sentido, es necesario repensar nuestro sistema federal dual prescrito en nuestro texto constitucional, de estados libres y soberanos y municipios libres, para reconocer un modelo federal más bien flexible o mixto, que se adecue a nuestra realidad política y social. Romper con las barreras conceptuales del federalismo que en gran medida han sido utilizadas como subterfugio político-jurídicos para la impunidad que, en lugar de servir de límite al poder central, han impedido forjar los debidos pesos y contrapesos en los estados y municipios.

\section{Bibliografía}

Aguilar Villanueva, Luis F. (2013), Gobernanza y gestión pública, México, FCE.

Benson, Nettie Lee (2012), La diputación provincial y el federalismo mexicano, México, Colegio de México.

Biscaretti di Ruffía, Paolo (2006), Derecho constitucional, México, FCE.

Blanco VAldÉs, Roberto L. (1994), El valor de la Constitución: separación de poderes, supremacia de la ley y control de constitucionalidad en los orígenes del Estado Libera, Madrid, Alianza Universidad.

BurdeAu, Georges (1985), Tratado de ciencia política, t. II., México, UNAM.

Burgoa, Ignacio (1996), Derecho constitucional mexicano, México, Porrúa.

Caminal, Miguel (2002), El federalismo pluralista. Del federalismo nacional al federalismo pluralista, Barcelona, Paidós.

Canudas O., Luis F. (1943), "Irreformabilidad de las decisiones fundamentales de la Constitución”, Revista de la Escuela de Jurisprudencia, México, UNAM, núm. 18.

CARbonell, Miguel (2003), "Federalismo en México: principios generales de distribución de competencias", Anuario de derecho constitucional latinoamericano, Uruguay, Konrad-Adenauer-Stiftung.

CArpizo, Jorge (2013), "Los principios jurídico-políticos fundamentales en la Constitución mexicana", Constitucionalismo. Dos siglos de su nacimiento en América Latina, México, UNAM.

(1972), "Sistema federal mexicano", Los sistemas federales del Continente Americano, México, FCE.

(1994), Estudios constitucionales, Porrúa-UNAM.

Chaires Zaragoza, Jorge (2018), Federalismo mixto. De un federalismo dual a un federalismo nacional, México, Universidad de Guadalajara. 
Dominice, Ch. (1978), "El federalismo en Suiza”, Boletín de Derecho Comparado, Instituto de Investigaciones Jurídicas, núm. 33, UNAM, pp. 255-311.

FAYA VIESCA, Jacinto (2014), El federalismo mexicano. Régimen constitucional del sistema federal, México, Porrúa.

GaGnon, Alain-G, y Lacovino, Raffaele (2008), Ciudadanía, federalismo y multinacionalismo. Debate sobre la aportación de Quebec, México, Universidad de Guadalajara.

Gaudreault-Desbiens, Jean-François (2006), "Federalismo y democracia", Boletín de derecho comprado, Instituto de Investigaciones Jurídicas, núm. 117, UNAM.

HäBerLe, Peter (2007), “Comparación constitucional y cultura de los modelos federales”, Revista de derecho constitucional europeo, No. 8, julio-diciembre.

Hartz, Louis (1994), La tradición liberal en los Estados Unidos, México, FCE.

Heller, Herman (1995), Teoría del Estado, México, FCE.

Hernández Díaz, Jaime (2012), "La primera república federal en Michoacán, 1823-1835", en: Vázquez, Josefina Zoraida y Serrano Ortega, José Antonio (Coords.), Práctica y fracaso del primer federalismo mexicano (1823-1835), México, El Colegio de México.

Huntington, Samuel P. (2004), ¿Quiénes somos? Los desafíos a la identidad nacional estadounidense, México, Paidós.

Levi, Lucio, Bobbio, Norberto; Matteucci, Nicola y Pasquino, Gianfranco (Coords., 1983), Diccionario de política, Madrid, España, Siglo XXI.

Medina Peña, Luis (2007), Invención del sistema político mexicano. Forma de gobierno y gobernabilidad en el siglo XIX. México, FCE.

Mier, Fray Servando Teresa de (2013), "Profecía del doctor Mier sobre la federación mexicana. Sesión del Congreso constituyente del 13 de diciembre de 1823", La revolución y la fe. Fray Servando Teresa de Mier, una antología genera, México, FCE-FLM-UNAM.

Olveda, Jaime (2012), “Jalisco y su primera experiencia federalista”, en: Vázquez, Josefina Zoraida y Serrano Ortega, José Antonio (Coords.), Práctica y fracaso del primer federalismo mexicano (1823-1835), México, El Colegio de México.

Ramos ArizPe, Miguel (1994), Discursos, Memorias e Informes, México, UNAM.

RabASA, Emilio (1986), El pensamiento político del constituyente de 1824, México, UNAM, Instituto de Investigaciones Jurídicas.

Rabell García, Enrique, Nieto Castillo, Gabriela y Jiménez Gómez, Juan Ricardo (2013), Federalismo en México, México, Universidad Autónoma de Querétaro - Miguel Ángel Porrúa.

RAPHAEL, Ricardo (2016), "Federalismo incongruente”, El Universal, [en línea] disponible en: http://www.eluniversal.com.mx/entradadeopinion/columna/ricardoraphael/ nacion/politica/2016/04/21/federalismo-incongruente (Consultada 21 de abril de 2016)

Reyes Heroles, Jesús (2007), El liberalismo mexicano, T.I., México, FCE. 
Rovila, Enoch Alberti (1986), Federalismo y cooperación en la República Federal Alemana, Madrid, Centro de Estudios Constitucionales.

Rovira Gaspar, María del Carmen (2009), "Filosofía y humanismo. La obra de los jesuitas criollos mexicanos", Revista de Hispanismo Filosófico, no. 14.

SÁnchez Silva, Carlos (2012), "De la unidad federalista a la disidencia centralista", en: Vázquez, Josefina Zoraida y Serrano Ortega, José Antonio (Coords.), Práctica y fracaso del primer federalismo mexicano (1823-1835), México, El Colegio de México.

Tena Ramírez, Felipe (2001), Derecho constitucional mexicano, México, Porrúa.

Tocqueville, Alexis (1998), La democracia en América, México, FCE.

Valero Flores, Carlos Norberto (2007), Municipio Libre en el marco del federalismo mexicano, Derecho y Obligaciones, México, Cámara de Diputados.

VÁzquez, Josefina Z. (1993), "Un viejo tema: el federalismo y el centralismo", Historia Mexicana, ejemplar dedicado a México e Hispanoamérica, Una reflexión historiográfica en el Quinto Centenario. II. 42 (3).

(2003), "Constitución Federal de los Estados Unidos Mexicanos, 1824. Contexto histórico del constituyente de 1824", México y sus constituciones, México, FCE.

(2012) "Del federalismo moderado al fracaso radical: Zacatecas", en: Vázquez, Josefina Zoraida y Serrano Ortega, José Antonio (Coords.), Práctica y fracaso del primer federalismo mexicano (1823-1835), México, El Colegio de México.

Verdú, Lucas (1976), Curso de derecho político, 2 tomos, Madrid, Tecnos, 1976. 